\title{
Colloidal Polymer Composites: Are Nano-Fillers Always Better for Improving Mechanical Properties?
}

\author{
D.K. Makepeace ${ }^{\mathrm{a}}$, P. Locatelli ${ }^{\mathrm{b}}$, C. Lindsay ${ }^{\mathrm{b}}$, J.M. Adams, $^{\mathrm{a}}$ and J.L. Keddie ${ }^{\mathrm{a},} \uparrow$ \\ ${ }^{a}$ Department of Physics, University of Surrey, Guildford, Surrey GU2 7XH, UK \\ ${ }^{b}$ Syngenta, Jealott's Hill International Research Centre, Bracknell, Berkshire RG42 6EY, UK
}

\section{Differential Scanning Calorimetry}

Differential scanning calorimetry (DSC) was carried out using a commercial instrument (Q1000, TA Instruments, New Castle, DE) to determine the polymer $T_{g}$ before and after the addition of the coalescing aid (Texanol ${ }^{\mathrm{TM}}$ ). Approximately $10 \mathrm{mg}$ of a dried film sample was placed in an aluminum pan in nitrogen. The temperature was equilibrated at -30 ${ }^{\circ} \mathrm{C}$ before heating to $120{ }^{\circ} \mathrm{C}$ at a ramp rate of $10^{\circ} \mathrm{C} / \mathrm{min}$. The temperature was then reduced to $-30{ }^{\circ} \mathrm{C}$ at a cooling rate of $10{ }^{\circ} \mathrm{C} / \mathrm{min}$ before re-heating to $120{ }^{\circ} \mathrm{C}$ at a ramp rate of $10{ }^{\circ} \mathrm{C} / \mathrm{min}$ to complete the cycle.

\section{Atomic Force Microscopy (AFM)}

AFM images were obtained using an atomic force microscope (NTEGRA, NT-MDT) and analysed using NT-MDT Nova software. An NT-MDT Au-coated cantilever (nominal spring constant of $0.05 \mathrm{~N} / \mathrm{m}$ ) was used. Images were obtained over an area of $2.5 \mu \mathrm{m} \times 2.5$ $\mu \mathrm{m}$.

\section{Scanning Electron Microscopy (SEM)}

SEM images of composites were obtained using a JEOL JSM-7100F electron microscope. Before imaging, samples were sputter coated with a $2 \mathrm{~nm}$ layer of Au. For crosssectional imaging, films were submerged in liquid nitrogen until frozen then fractured using plastic tweezers. Images were obtained using an accelerating voltage of either 5 or $10 \mathrm{kV}$. Images of individual calcium carbonate particles were obtained when using an accelerating voltage of $5 \mathrm{kV}$. Samples were sputter-coated with $2 \mathrm{~nm}$ of Au prior to imaging. 


\section{SUPPORTING MATERIAL}

Dynamic Scanning Calorimetry (DSC)

DSC was used to obtain the $T_{g}$ of $\mathrm{P}(\mathrm{St}-\mathrm{BA}-\mathrm{AA})$ before and after the addition of $10 \mathrm{wt} . \%$ Texanol $^{\mathrm{TM}}$ plasticizer.
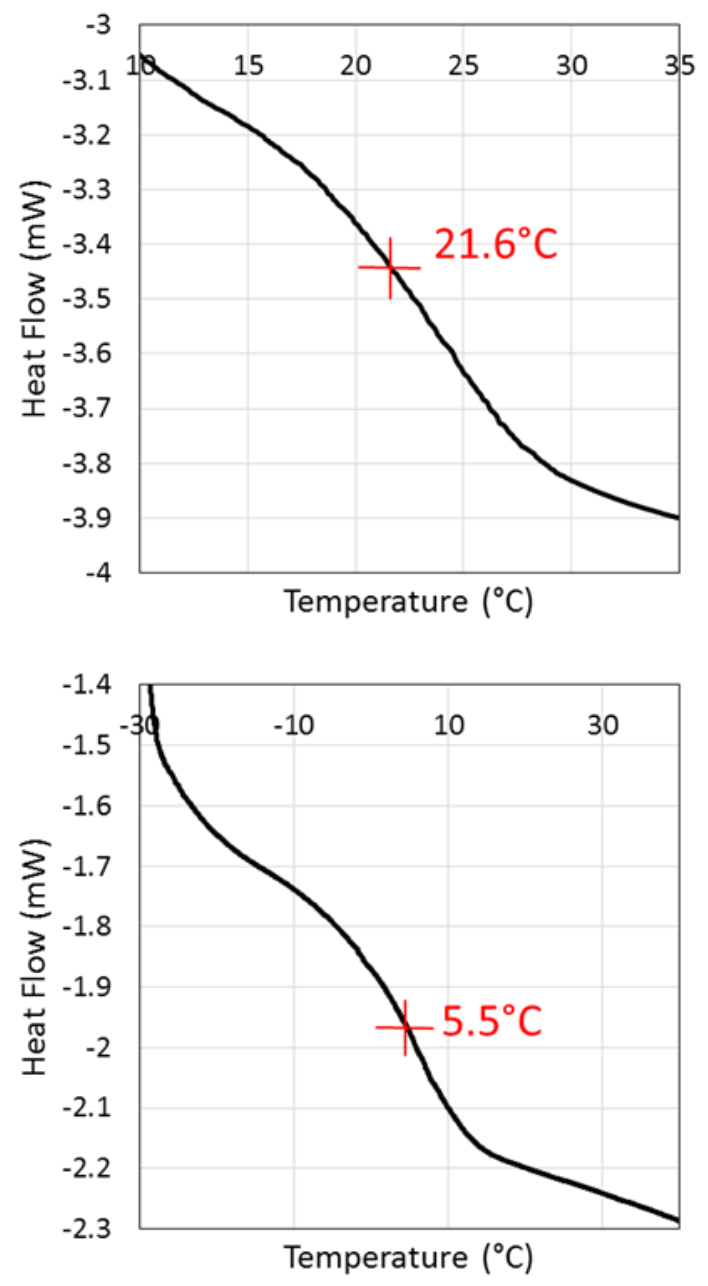

Figure S1. DSC thermograms for P(St-BA-AA) (top) and with P(St-BA-AA) with 10 wt.\% $\mathrm{Texanol}^{\mathrm{TM}}$ plasticizer added before film casting (bottom). The results from the first heating are shown. The second heating found similar values $\left(21.8{ }^{\circ} \mathrm{C}\right.$ and $\left.4.6^{\circ} \mathrm{C}\right)$.

The DSC thermogram for $\mathrm{P}(\mathrm{St}-\mathrm{BA}-\mathrm{AA})$ shows a broad transition in the range from approximately $15^{\circ} \mathrm{C}$ to $28^{\circ} \mathrm{C}$, with midpoint values of $21.6^{\circ} \mathrm{C}$ and $21.8^{\circ} \mathrm{C}$, for heating and cooling, respectively. The thermogram for $\mathrm{P}(\mathrm{St}-\mathrm{BA}-\mathrm{AA})$ with $10 \mathrm{wt} . \%$ added plasticizer added shows a narrower transition ranging from approximately $0{ }^{\circ} \mathrm{C}$ to $10{ }^{\circ} \mathrm{C}$. Mid-point $T_{g}$ values of $5.5^{\circ} \mathrm{C}$ and $4.6{ }^{\circ} \mathrm{C}$ were obtained from the first and second heating, respectively. This relatively small decrease in $T_{\mathrm{g}}$ value upon re-heating indicates that no significant amount of plasticizer was lost from the DSC pan. 


\section{SUPPORTING MATERIAL}

\section{Stress-Strain and Failure Analysis}

Figure $\mathrm{S} 2$ shows representative stress-strain curves of $\mathrm{P}(\mathrm{St}-\mathrm{BA}-\mathrm{AA}) /$ calcium carbonate composites at $T=13{ }^{\circ} \mathrm{C}$, which is approximately $8{ }^{\circ} \mathrm{C}$ below the $T_{g}$ of P(St-BA-AA).
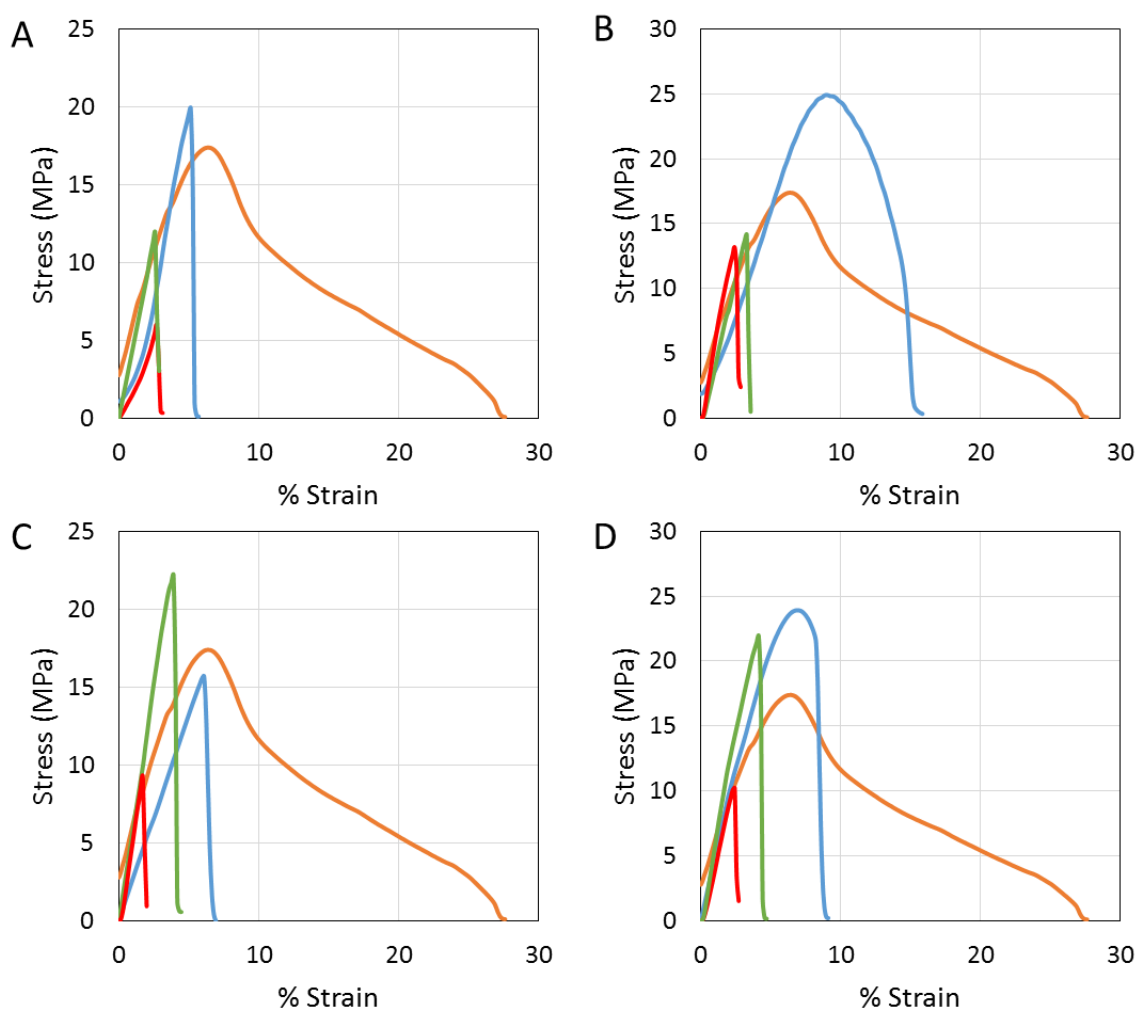

Figure S2. Representative stress-strain curves obtained at $T=13{ }^{\circ} \mathrm{C}$ for $\mathrm{P}(\mathrm{St}-\mathrm{BA}-$

AA)/calcium carbonate composites for increasing calcium carbonate volume fractions, $\phi_{\mathrm{CC}}$ : 0.00 (orange), 0.10 (blue), 0.20 (green), 0.30 (red), and 0.35 (purple). Four different particle size ratios, $\alpha$, are presented: (A) 0.4; (B) 4; (C) 17; and (D) 26.

The data shown in Figure S2 highlight a significant reduction in the average strain at failure for all samples, relative to the results at $30{ }^{\circ} \mathrm{C}$, regardless of $\phi_{\mathrm{CC}}$ and $\alpha$. Figure S2 also shows that the stress at failure is significantly higher at $13{ }^{\circ} \mathrm{C}$ than at $30{ }^{\circ} \mathrm{C}$. The highest stress at failure is at $25 \mathrm{MPa}$ when $\alpha=4$ and $\phi_{\mathrm{CC}}=0.10$. With other size ratios and concentrations, most values fall in the range from 10 to $20 \mathrm{MPa}$.

Figure $\mathrm{S} 3$ shows the average strain at failure for $\mathrm{P}(\mathrm{St}-\mathrm{BA}-\mathrm{AA}) /$ calcium carbonate composites at $T=13{ }^{\circ} \mathrm{C}$, which is obtained from the analysis of the data in Figure S2. 


\section{SUPPORTING MATERIAL}

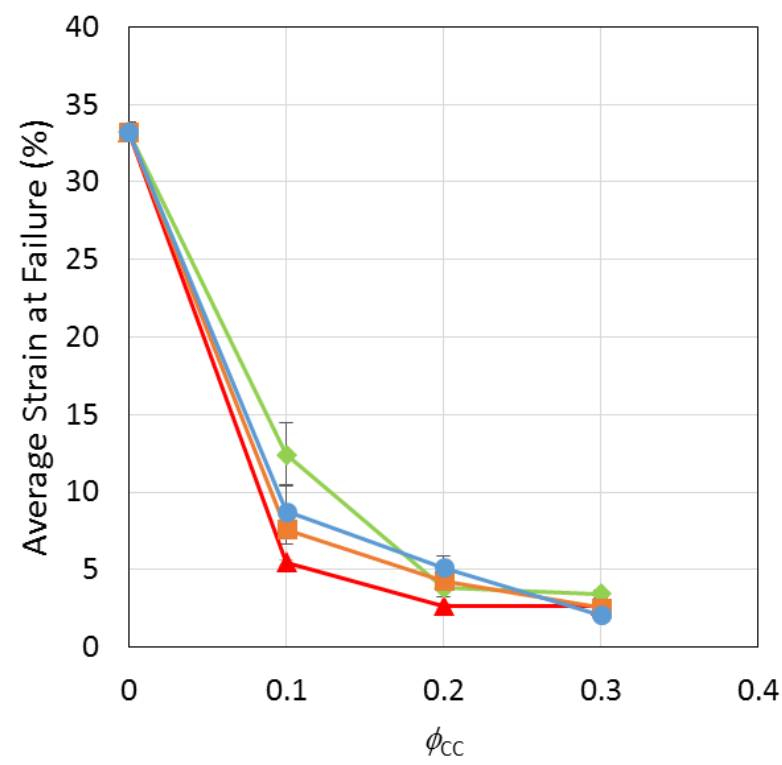

Figure S3. Average strain at failure for $\mathrm{P}(\mathrm{St}-\mathrm{BA}-\mathrm{AA}) /$ calcium carbonate composites at $T=$ $13{ }^{\circ} \mathrm{C}$ as a function of $\phi_{\mathrm{CC}}$ where $\alpha=0.4$ (red triangles), $\alpha=4$ (green diamonds), $\alpha=17$ (orange squares), and $\alpha=26$ (blue circles).

When $T=13^{\circ} \mathrm{C}$, the average strain at failure when $\phi_{C C}=0$ is $33 \%$, which is considerably lower than the value when $T=30^{\circ} \mathrm{C}(\sim 200 \%)$ or when $T=13{ }^{\circ} \mathrm{C}(\sim 300 \%)$ when the sample has been plasticised. As $\phi_{\mathrm{CC}}$ is increased, a sharp decrease in the average strain at failure is observed, and all samples experience failure below $15 \%$ strain when $\phi_{\mathrm{CC}}=0.1$. Thus, at 13 ${ }^{\circ} \mathrm{C}$, brittle fracture occurs for all samples when $\phi_{\mathrm{CC}}=0.10$, whereas when $T=30^{\circ} \mathrm{C}$ brittle failure does not occur until $\phi_{\mathrm{CC}}=0.24$ when $\alpha=0.4$ and until $\phi_{\mathrm{CC}}=0.35$ when $\alpha \geq 4$. When $\alpha=0.4$, the decrease in the average strain at failure, when $\phi_{\mathrm{CC}}=0.10$ and 0.20 , is greater than when $\alpha \geq 4$. This may be because, although all size ratios introduce the same volume of voids (points where fracture may begin), smaller particles introduce a greater number of individual voids. When $\phi_{\mathrm{CC}}=0.30$, all size ratios exhibit a similar average strain at failure of only about $3 \%$. 


\section{SUPPORTING MATERIAL}

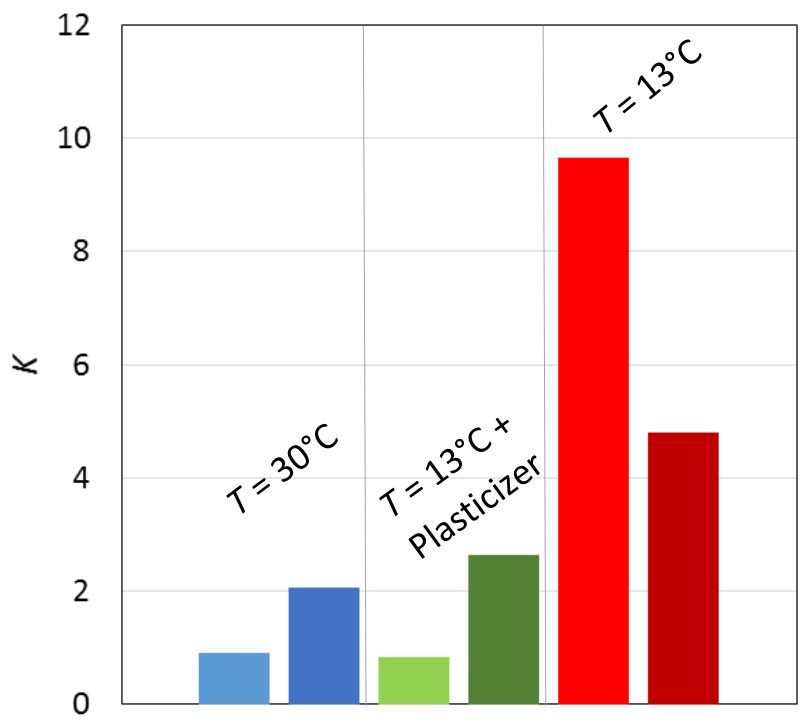

Figure S4. Bar chart showing average $K$ values for non-plasticised samples with $T=30^{\circ} \mathrm{C}$ (blue shades) and $T=13{ }^{\circ} \mathrm{C}$ (red shades) and plasticised samples with $T=13{ }^{\circ} \mathrm{C}$ (green shades). Lighter shaded bars (on the left side) show data for $\alpha<1$. Darker shaded bars (on the right) show data for $\alpha>1$. 


\section{SUPPORTING MATERIAL}

\section{DMA Data}
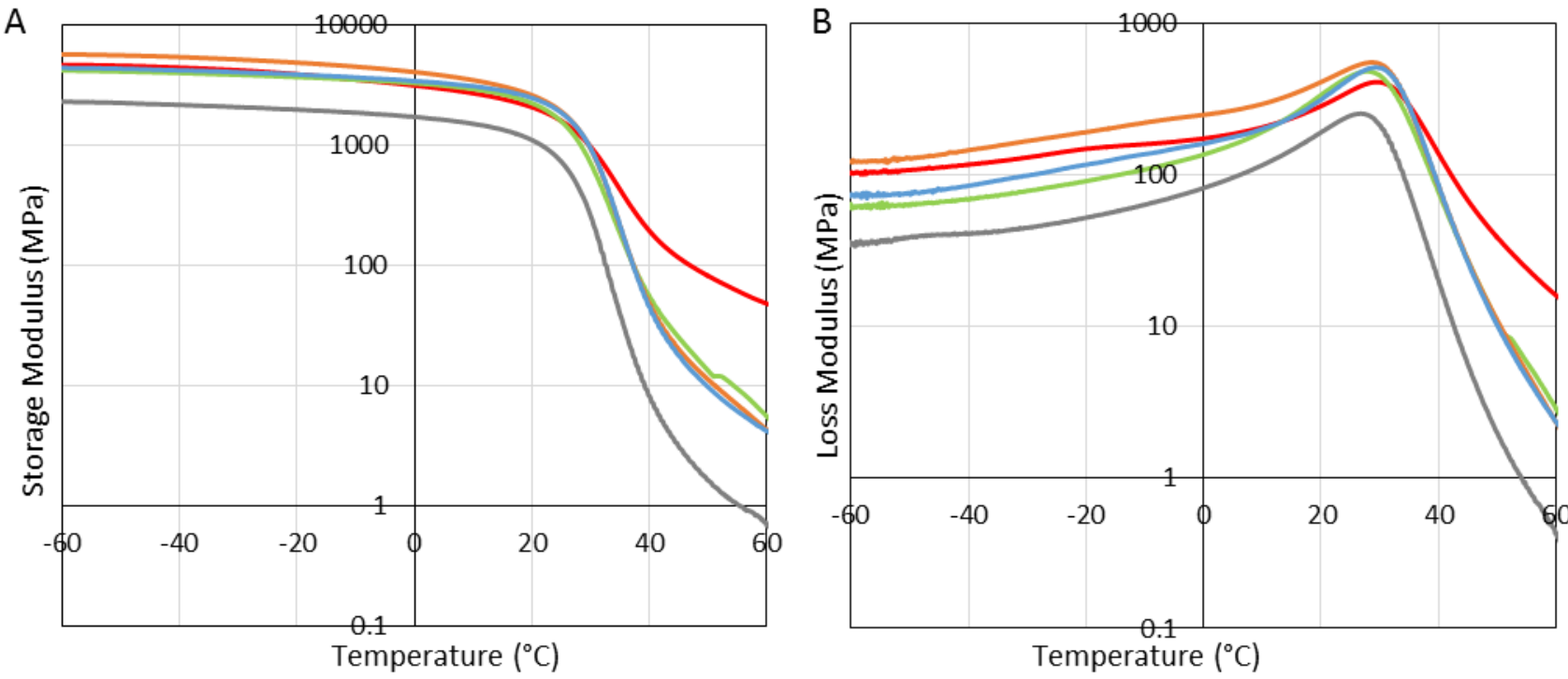

Figure S5. (A) Storage modulus and (B) loss modulus for P(St-BA-AA)/calcium carbonate composites as a function of temperature where $\phi_{\mathrm{CC}}=0.2$ and for four particle size ratios: $\alpha=$ 0.4 (red), $\alpha=4$ (green), $\alpha=17$ (orange), $\alpha=26$ (blue). Data for P(St-BA-AA) without any calcium carbonate $\left(\phi_{\mathrm{CC}}=0.00\right)$ are shown for comparison (grey).

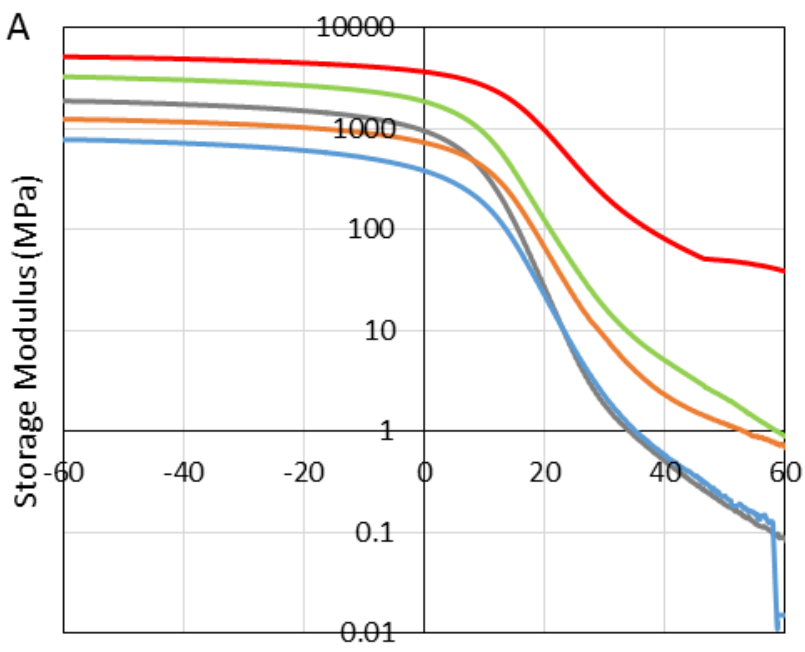

Temperature $\left({ }^{\circ} \mathrm{C}\right)$

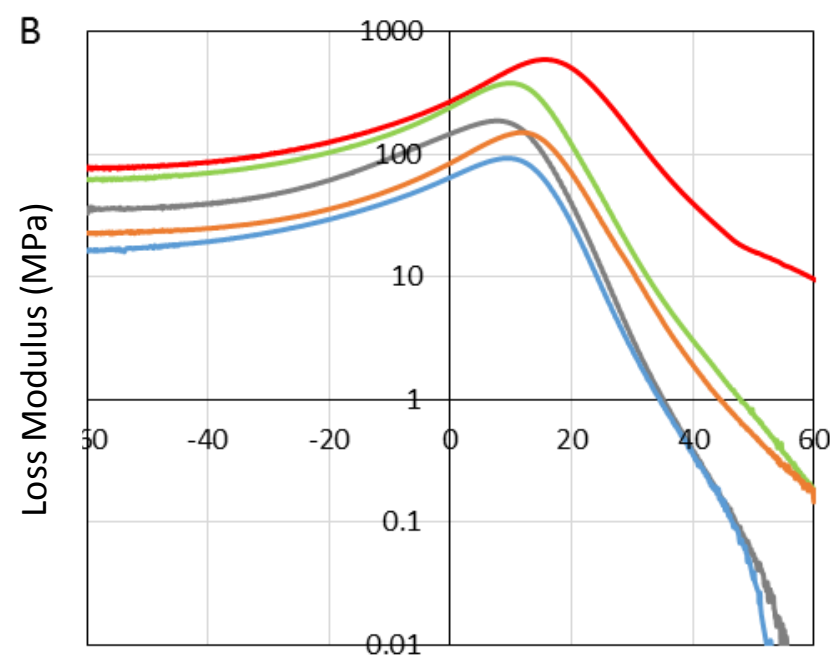

Temperature $\left({ }^{\circ} \mathrm{C}\right)$

Figure S6. (A) Storage modulus and (B) loss modulus for P(St-BA-AA)/calcium carbonate composites with $10 \mathrm{wt} . \%$ plasticizer as a function of temperature where $\phi_{\mathrm{CC}}=0.20$ and for four particle size ratios: $\alpha=0.4$ (red), $\alpha=4$ (green), $\alpha=17$ (orange), $\alpha=26$ (blue). Data for $\mathrm{P}(\mathrm{St}-\mathrm{BA}-\mathrm{AA})$ without any calcium carbonate $\left(\phi_{\mathrm{CC}}=0.00\right)$ are shown for comparison (grey). 


\section{SUPPORTING MATERIAL}
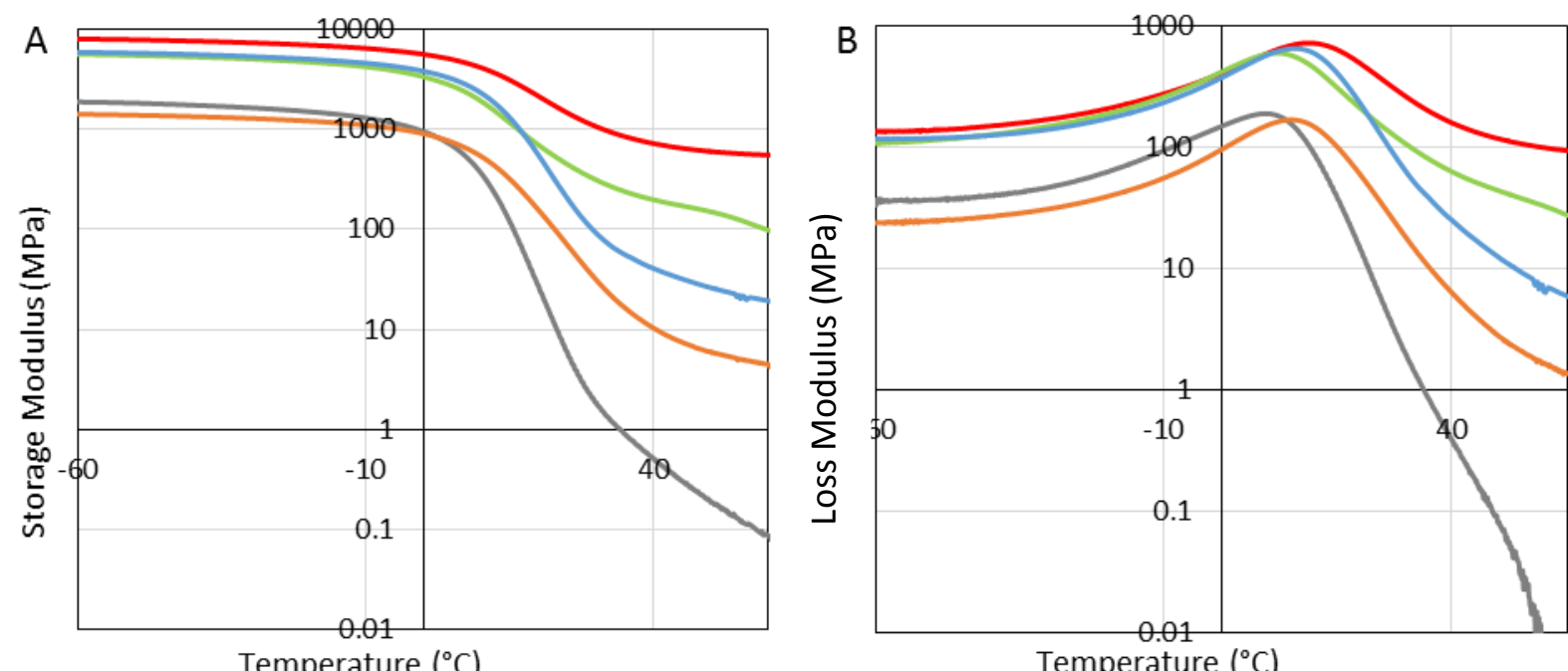

Figure S7. (A) Storage modulus and (B) loss modulus for P(St-BA-AA)/calcium carbonate composites with $10 \mathrm{wt} . \%$ plasticizer as a function of temperature where $\phi_{\mathrm{CC}}=0.35$ and for four particle size ratios: $\alpha=0.4$ (red), $\alpha=4$ (green), $\alpha=17$ (orange), $\alpha=26$ (blue). Data for $\mathrm{P}\left(\right.$ St-BA-AA) without any calcium carbonate $\left(\phi_{\mathrm{CC}}=0.00\right)$ are shown for comparison (grey).

Examining the loss moduli in Figures S5 and S6, it is apparent that the peak, which occurs at the polymer's $T_{g}$, varies slightly in its position along the x-axis (temperature); this is not the case in Figure S4 (without any added plasticizer). This variability occurs only in samples containing the plasticizer; therefore, it is a strong indication that some plasticizer is lost from the sample after the films have been cast. It is most likely that some plasticizer is evaporated when heating under the IR lamp, as it is a volatile substance.

\section{Creep Data}
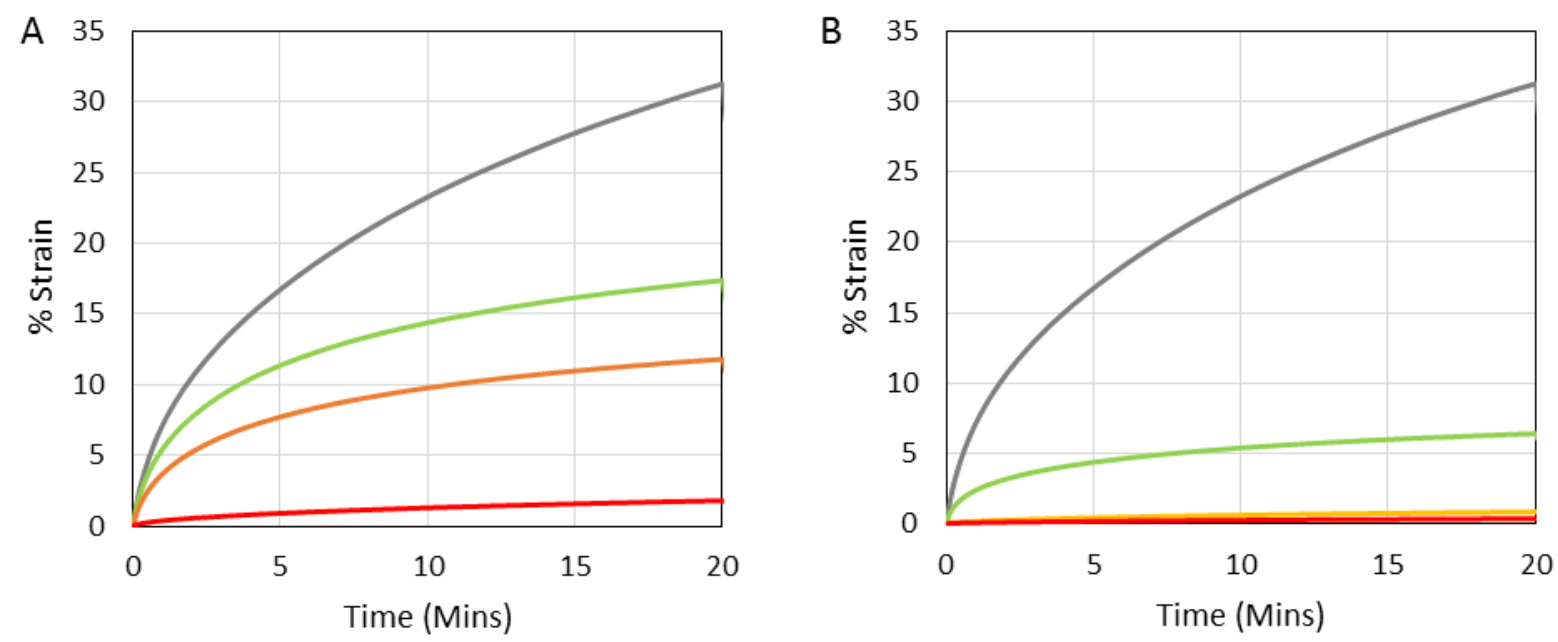

Figure S8. Creep results for $\mathrm{P}(\mathrm{St}-\mathrm{BA}-\mathrm{AA}) /$ calcium carbonate composites, obtained at $T=30$ ${ }^{\circ} \mathrm{C}$, where (A) $\alpha=26$ and (B) $\alpha=0.4$. The experiments studied four different volume fractions of calcium carbonate: $\phi_{\mathrm{CC}}=0.00$ (grey); $\phi_{\mathrm{CC}}=0.10$ (green); $\phi_{\mathrm{CC}}=0.20$ (orange); and $\phi_{\mathrm{CC}}=0.30(\mathrm{red})$. 


\section{SUPPORTING MATERIAL}

For both size ratios, it is clear that as $\phi_{C C}$ is increased, the amount of strain is lower and the rate of strain becomes slower. It is also apparent that there is less strain and a slower strain rate when $\alpha=0.4$ compared to when $\alpha=26$ for a particular value of $\phi_{C C}$.
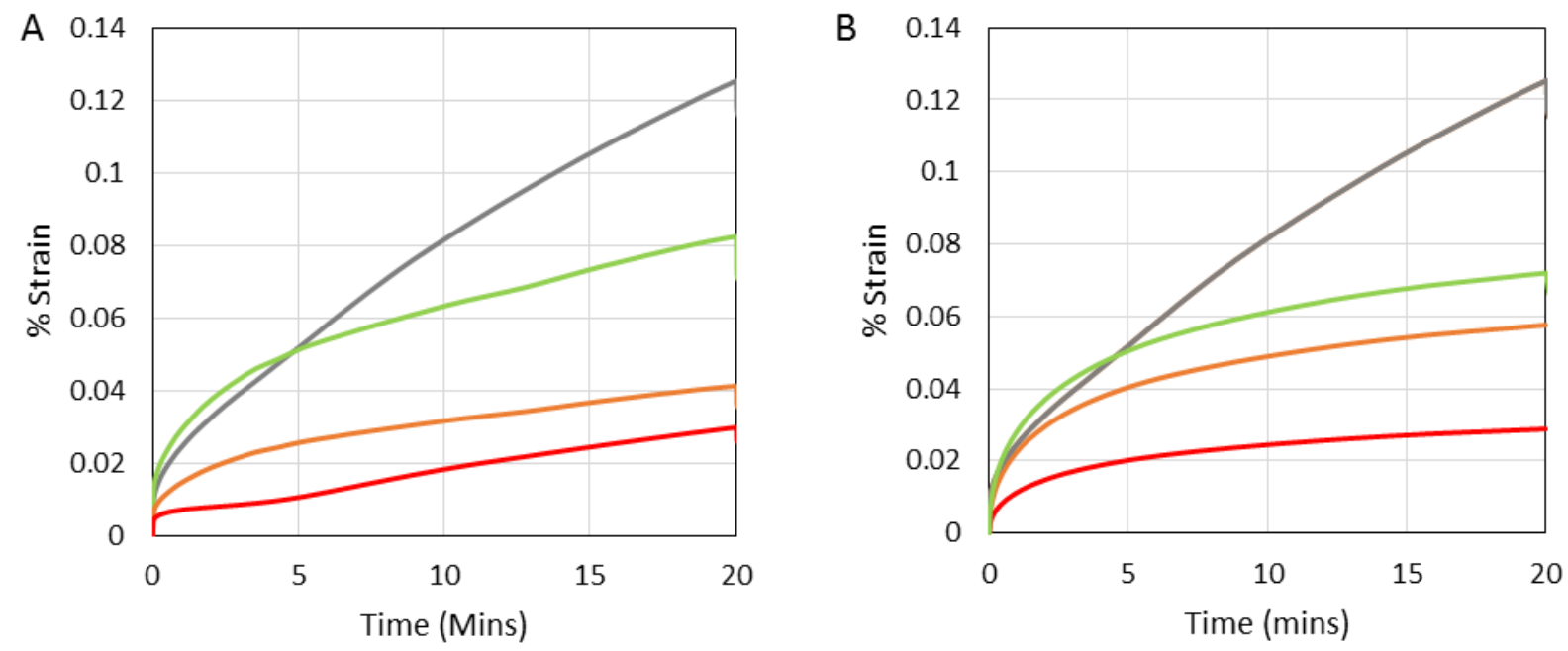

Figure S9. Creep results for $\mathrm{P}(\mathrm{St}-\mathrm{BA}-\mathrm{AA}) /$ calcium carbonate composites, obtained at $T=13$ ${ }^{\circ} \mathrm{C}$, when (A) $\alpha=26$ and (B) $\alpha=0.4$. $\phi_{\mathrm{CC}}=0.00$ (grey), $\phi_{\mathrm{CC}}=0.10$ (green), $\phi_{\mathrm{CC}}=0.20$ (orange), and $\phi_{\mathrm{CC}}=0.30$ (red).

For non-plasticised samples, at $T=13^{\circ} \mathrm{C}$ (below the $T_{g}$ of $\mathrm{P}(\mathrm{St}-\mathrm{BA}-\mathrm{AA})$, very slow strain is exhibited in Figure S8, even when $\phi_{C C}=0.0$, because the polymer is glassy below its $T_{g}$. As $\phi_{C C}$ is incrementally increased, the strain slows further. Comparing Figure S8A and Figure $\mathrm{S} 8 \mathrm{~B}$, there appears to be little effect of particle size ratio. The total strain is very low for each.
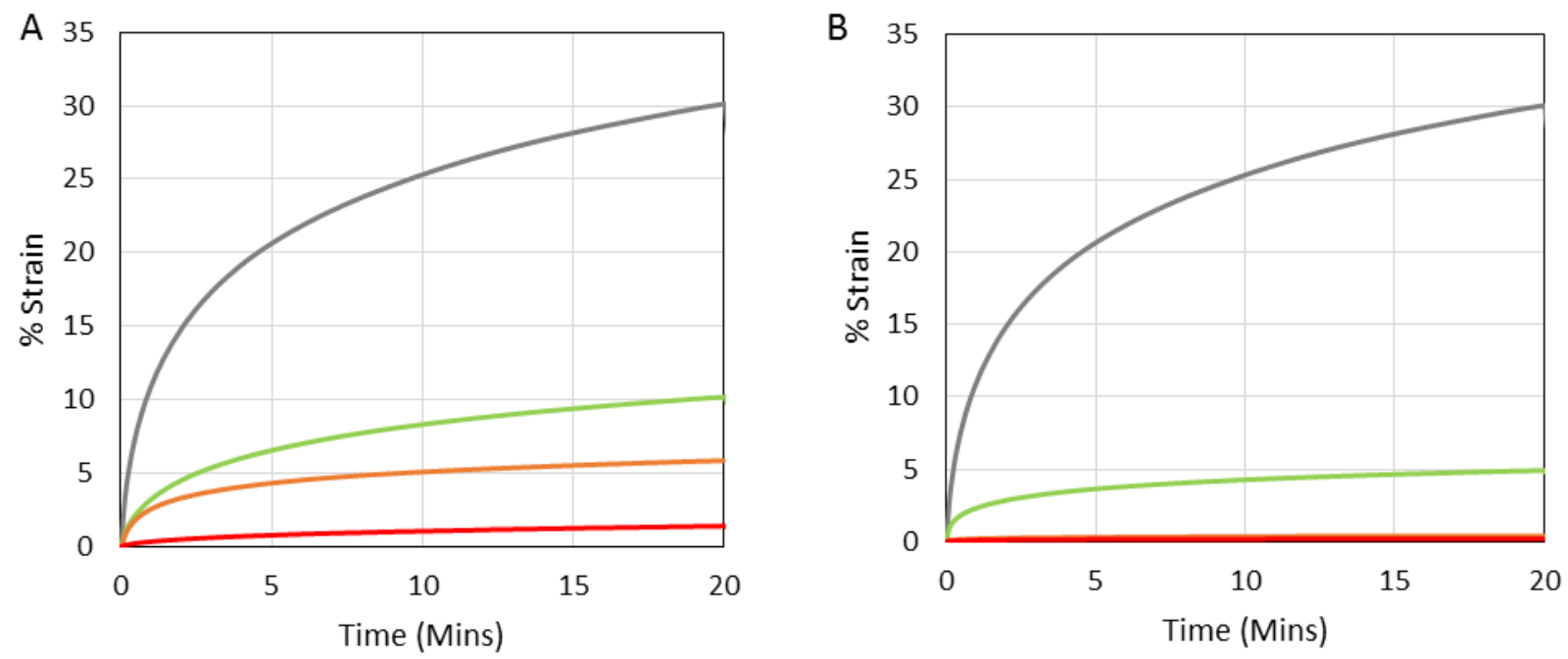

Figure S10. Creep results for P(St-BA-AA)/calcium carbonate composites with $10 \mathrm{wt} . \%$ plasticizer, obtained at $T=13{ }^{\circ} \mathrm{C}$, where (A) $\alpha=26$ and (B) $\alpha=0.4 . \phi_{\mathrm{CC}}=0.00$ (grey), $\phi_{\mathrm{CC}}=$ 0.10 (green), $\phi_{\mathrm{CC}}=0.20$ (orange), and $\phi_{\mathrm{CC}}=0.30($ red) . 


\section{SUPPORTING MATERIAL}

The creep behavior of plasticized samples at $T=13{ }^{\circ} \mathrm{C}$, shown in Figure $\mathrm{S} 9$, is remarkably similar to that of non-plasticised samples at $T=30^{\circ} \mathrm{C}$ (in the rubbery state). Again, incremental increases in $\phi_{C C}$ result in a slowing of the strain rate for both size ratios. Importantly, an increase in $\phi_{C C}$ results in a slower strain rate and lower amount of strain when $\alpha=0.4$ compared to when $\alpha=26$.

\section{Creep Enhancement}
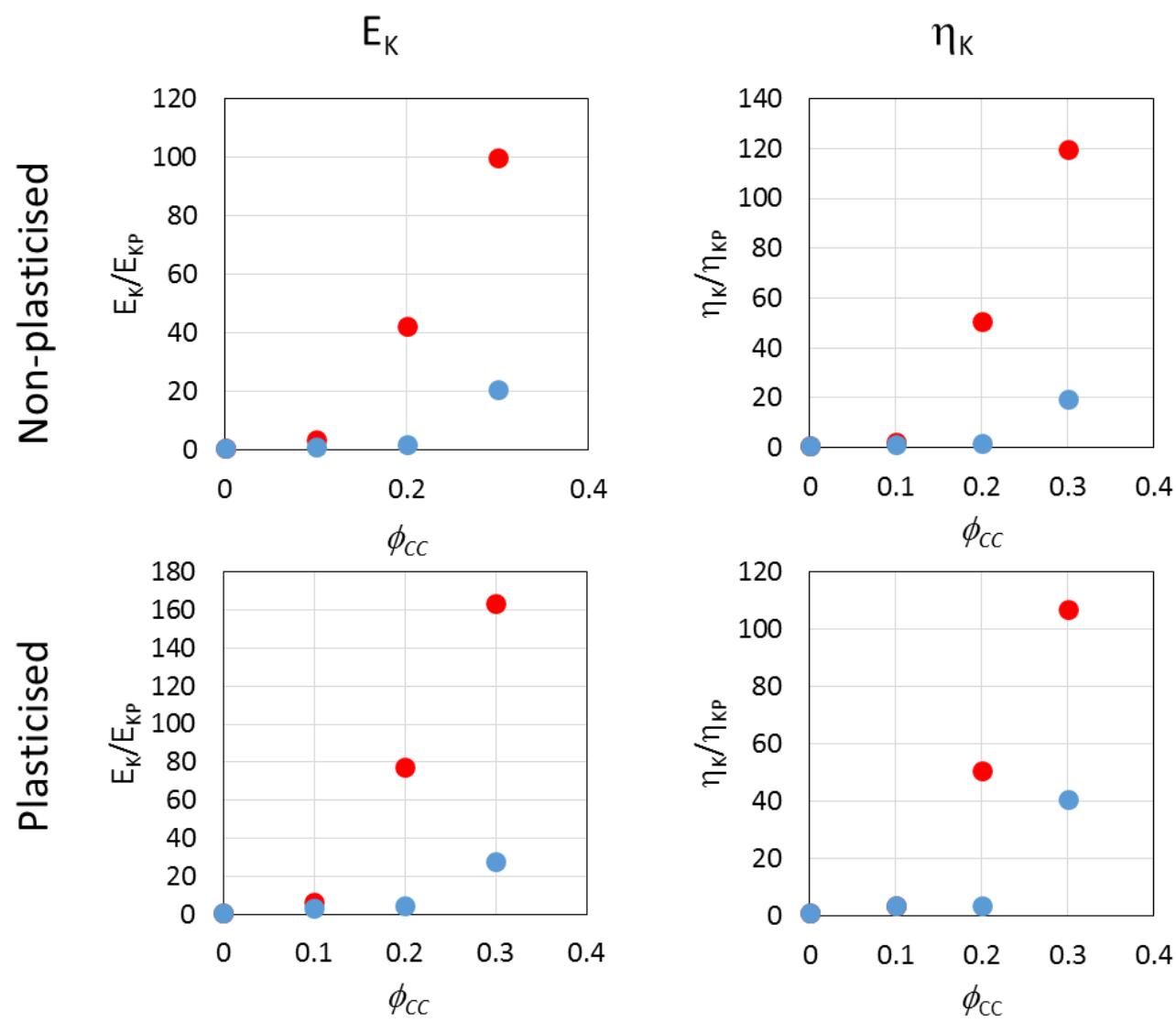

Figure S11. Enhancement factor of the viscoelastic components of the Burger's model, $\mathrm{E}_{\mathrm{K}}$ (left column) and $\eta_{\mathrm{K}}$ (right column), for $\mathrm{P}(\mathrm{St}-\mathrm{BA}-\mathrm{AA}) /$ calcium carbonate composites as a function of $\phi \mathrm{CC}_{\mathrm{C}}$ for non-plasticised samples at $T=30{ }^{\circ} \mathrm{C}$ (top row) and plasticised samples at $T=13^{\circ} \mathrm{C}$ (bottom row). Data are presented for two different size ratios: $\alpha=0.4$ (red) and $\alpha=$ 26 (blue).

Both of the viscoelastic parameters, obtained from fitting the Burger's model to the creep data, are presented in Figure S10. They are presented as enhancement factors, which are found by dividing by the value obtained from the polymer without any calcium carbonate addition. Both parameters increase with increasing $\phi_{C C}$, which are consistent with the enhancements for the Hookean elastic and Newtonian viscous components, and are presented in the main text. For instance, significant enhancement for both parameters is exhibited at $\phi_{C C}$ $=0.2$ when $\alpha=0.4$, while the sample in which $\alpha=26$ shows very little enhancement. The main text presents the structural arguments as to why this difference between the size ratios occurs. 